Diabetologia 10, 303-308 (1974)

(C) by Springer-Verlag 1974

\title{
Effect of Cytochalasin B on Hexose Transport and Glucose Metabolism in Pancreatic Islets*
}

\author{
M. L. McDaniel, S. King, S. Anderson, J. Fink and P. E. Lacy \\ Department of Pathology, Washington University School of Medicine, St. Louis, Missouri, USA
}

Received: December 21, 1973, and in revised form: April 1, 1974

\begin{abstract}
Summary. The effect of cytochalasin B on hexose transport into rat pancreatic islets isolated by collagenase digestion has been investigated. A double radioactive label procedure has permitted correction for label present in the extracellular space and determined that the permeability of the B-cell membrane of collagenase treated islets to L-glucose and sucrose is insignificant under the conditions employed. Cytochalasin B (15 $\mu \mathrm{g} / \mathrm{ml})$ significantly inhibits the initial rate of uptake of $D$ glucose, 3-0-methyl-D-glucose, and 2-deoxy-D-glucose at temperatures of $20^{\circ} \mathrm{C}$ and $37^{\circ} \mathrm{C}$ when islets are preincubated $(20 \mathrm{~min})$ in the presence of cytochalasin $\mathbf{B}$.
\end{abstract}

No significant inhibition is observed on the initial rate of uptake of $\mathrm{D}$-glucose at a temperature of $37^{\circ} \mathrm{C}$ if cytochalasin $B$ is present only in the incubation medium. The production of ${ }^{14} \mathrm{CO}_{2}$ from uniformly ${ }^{14} \mathrm{C}$ labeled $\mathrm{D}$ glucose is unaltered in the presence of cytochalasin B over a $2 \mathrm{~h}$ incubation period.

Key words: Pancreatic islet, B-cell, cytochalasin B, transport, collagenase digestion, D-glucose, L-glucose, 2-deoxy-D-glucose, 3-0-methyl-D-glucose, sucrose, dimethyl-sulfoxide.
Cytochalasin B has been shown by Orci et al. $[1,2]$ to disrupt the structure and organization of microfilaments in the pancreatic B-cell. Cytochalasin B (1$10 \mu \mathrm{g} / \mathrm{ml}$ ) enhanced the secretion of insulin induced by glucose, theophylline, and sulfonylureas in isolated rat islets, and Lacy et al. [3] have shown that cytochalasin $\mathrm{B}(5-20 \mu / \mathrm{ml})$ produced a significant increase in the rates of both the first and second phases of glucoseinduced insulin release of isolated rat islets maintained in vitro by perifusion. In this latter study, cytochalasin $B$ was also shown to enhance significantly the monophasic pattern of insulin release induced by tolbutamide. The enhancing effect of cytochalasin B on glucose and tolbutamide induced insulin release required the continued presence of cytochalasin B and its effect was rapidly reversible on removal of this agent.

Recent studies have directed attention to the cell membrane rather than the microfilamentous structure of cells as being a possible primary site of action of cytochalasin B. For example, cytochalasin B has been shown by Kletzien et al. [4] in 1972 to inhibit 2-deoxyD-glucose uptake in chick embryo fibroblasts and epithelial cells from rat liver, and Estensen et al. [5] reported that cytochalasin B inhibited the transport of D-glucose, 2-deoxy-D-glucose, and glucosamine by Novikoff hepatoma cells in culture.

The purpose of the present investigation is to determine whether cytochalasin B alters the initial rate of uptake of $\mathrm{D}$-glucose, 3-O-methyl-D-glucose, and 2-deoxy-D-glucose into rat pancreatic islets isolated by the collagenase technique.

1. This paper was supported by U.S.P.H.S. Grants AM 03373 and AM 06181

\section{Materials and Methods}

In the transport and metabolism studies to be described, islets were isolated by the collagenase technique described by Lacy et al. [6, 7] from male albino rats weighing from $200-300 \mathrm{~g}$. All incubations were accomplished with a bicarbonate buffer [8] containing $\mathrm{Ca}$ (5.0 mequiv./L) and albumin $(0.5 \% \mathrm{w} / \mathrm{v}$; bovine plasma albumin, Armour Pharmaceutical Company, Chicago, Illinois). Individual experiments were performed with either islets collected from one pancreas or pooled islets collected from two pancreases carried through the isolation procedure simultaneously. Radioactive chemicals were supplied by both New England Nuclear and Amersham/Searle. The radioactive isotopes used were D-glucose-U-14 C, 3-O-methyl-glucose-- ${ }^{14} \mathrm{C}$, 2-deoxy-Dglucose- ${ }^{14} \mathrm{C}$, D-glucose- $6^{3} \mathrm{H}$, and sucrose- ${ }^{3} \mathrm{H}$. D-glucose was obtained from the National Bureau of Standards, Washington, D.C.; 3-O-methyl-D-glucose, and 2deoxy-D-glucose from Sigma Chemical Co., St. Louis, Mo. Cytochalasin B (abbreviated cyto-B) was obtained from Imperial Chemical Industries, London, England. Hydroxide of Hyamine-10X, PPO, and POPOP were obtained from Packard Instrument Co., and toluene, dimethyl-sulfoxide (abbreviated DMS), and sucrose were supplied by Fisher Scientific Co. A Packard TriCarb, Model 4322 liquid scintillation spectrometer was used in radioactive isotope measurements.

\section{Non-Wash Procedure}

This non-wash procedure is similar to that previously described by Hellman et al. [9]. Twenty-five pancreatic islets were collected in small glass vials (11 $\mathrm{mm} \mathrm{ID} \times 20 \mathrm{~mm}$ height) containing $200 \mu \mathrm{l}$ of 
Krebs-ringer buffer at $4^{\circ}$ and $\mathrm{pH} 7.4$ which contained $1.6 \mathrm{mM}$ D-glucose and $0.5 \%(\mathrm{w} / \mathrm{v})$ bovine plasma albumin. The collecting fluid was removed with the aid of a micropipette and a dissecting microscope, and an equal volume of preincubation medium added. The vials were then placed on a Dubnoff metabolic shaker (100 strokes/min) in scintillation vials equipped with rubber stoppers for subsequent shaking and gassing with $\mathrm{O}_{2}(95 \%)$ and $\mathrm{CO}_{2}(5 \%)$. Transport studies were made at both temperatures of $20^{\circ}$ and $37^{\circ} \mathrm{C}$. The preincubation medium did not contain glucose and/or the hexose whose transport was being measured. A preincubation period of 20 min was employed and two experimental conditions were used in which the preincubation medium 1) contained cytochalasin B (15 $\mu \mathrm{g} /$ $\mathrm{ml}$ ) or 2) the agent was absent. Cytochalasin $B$ was dissolved in dimethyl-sulfoxide (stock solution $3.5 \mathrm{mg} / \mathrm{ml}$ ) and dimethyl-sulfoxide was present at $0.4 \%$ in the incubating mediums. After the pre-incubation period, the medium was removed and $150 \mu l$ of incubation medium containing a radioactive labeled extracellular and intracellular marker $\left({ }^{14} \mathrm{C}\right.$ and $\left.{ }^{3} \mathrm{H}\right)$ was added. The vials were then incubated for designated periods of time.

At the end of the incubation period, the medium was removed and the vials containing the islets immediately frozen in liquid nitrogen. The frozen vials were then transfered to a lyophilizing tube $[10]$ maintained at dry ice temperature, and then transfered to a constant temperature box at $-40^{\circ}$ for lyophilization at a vacuum equivalent of $0.01 \mathrm{~mm} \mathrm{Hg}$ or less for $36 \mathrm{~h}$. The lyophylizing tubes were removed from the cold box and evacuation continued until the contents reached room temperature. The lyophilized islets were then transfered with a micro-dissecting needle from the original incubation vial to a scintillation vial with the aid of a dissecting microscope. The islets were digested in $100 \mu \mathrm{l}$ of Hyamine- $10 \mathrm{X}$ at $37^{\circ} \mathrm{C}$ for one hour and then counted for double label isotope contents with a liquid scintillation spectrometer. Corrections were made for any loss of islets occuring during the experiment, and the final quantitation was based on the number of lyophilized islets transfered to the scintillation vial for digestion. The observed cpms were equated to the amount of hexose by comparison with external standards consisting of $\mathbf{3} \mu \mathrm{l}$ of incubation medium dissolved in $100 \mu \mathrm{l}$ of Hyamine-10X. The intracellular hexose content is expressed as picomoles $\left(10^{-12}\right.$ moles $)$ per islet for the designated incubation period.

\section{Wash Procedure}

This procedure is also similar to that described by Hellman et al. [11] and consists of removing the labeled incubation medium containing both extracellular and intracellular markers and washing with a complete medium at $0^{\circ}$ minus the labeled isotopes and cytochalasin B. Each vial was washed four times with one minute of elapsed time per wash. After the final wash, the islets were dissolved in $100 \mu \mathrm{l}$ of Hyamine$10 \mathrm{X}$ and incubated for one hour at $37^{\circ} \mathrm{C}$. After this incubation time, the entire glass incubation vial was transfered to a scintillation vial and counted for double label isotope content.

\section{${ }^{14} \mathrm{CO}_{2}$ Production}

The islets contained in glass vials were placed in larger scintillation vials which held a circular piece of filter paper and were equipped with rubber stoppers. The islets were preincubated for $25 \mathrm{~min}$ in $200 \mu \mathrm{l}$ of glucose-free medium which contained cytochalasin B $(15 \mu \mathrm{g} / \mathrm{ml})$. At the end of the preincubation period, the medium was removed and $170 \mu \mathrm{l}$ of incubation medium containing cytochalasin $\mathrm{B}$ and uniformly labeled ${ }^{14} \mathrm{C}$ D-glucose was added. The vials were gassed for $60 \mathrm{sec}$ with $\mathrm{O}_{2}(95 \%) / \mathrm{CO}_{2}(5 \%)$ and incubated for $2 \mathrm{~h}$ in a closed system at $37^{\circ} \mathrm{C}$. The incubation was terminated by the injection of $100 \mu \mathrm{l}$ of $0.1 \mathrm{~N} \mathrm{HCl}$ into the islet incubation vial and $100 \mu \mathrm{l}$ of Hyamine-10X into the filter paper. The scintillation vials were then shaken in a Dubnoff shaker for two hours at room temperature, the inner vial removed, and the filter paper counted for radioactive isotope content.

\section{Results}

\section{D-Glucose Uptake Using L-Glucose and Sucrose as Extracellular Markers}

The uptake of an insulin stimulatory concentration of $\mathrm{D}$-glucose, $16.5 \mathrm{mM}$ was studied using both L-glucose and sucrose as extracellular markers. In Fig. 1 is

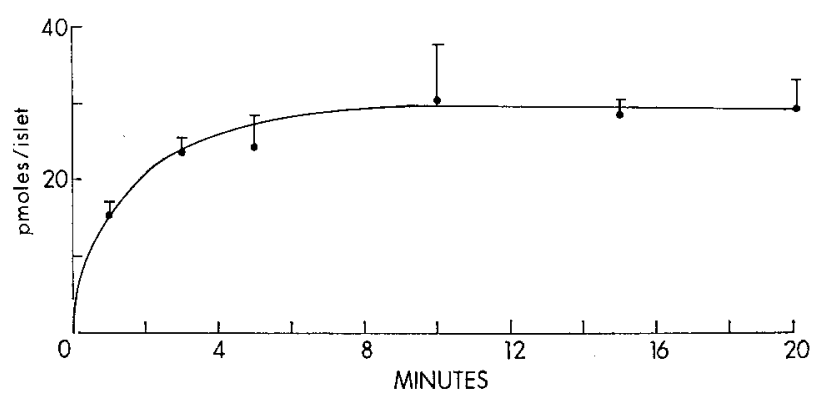

Fig. 1. Time-study of D-glucose uptake. After a preincubation period of $20 \mathrm{~min}$ in a glucose-free media, islets were incubated for different periods of time in media containing $16.5 \mathrm{mM} \mathrm{D}-\left(6-^{3} \mathrm{H}\right)$-glucose (sp. act. $0.6 \mathrm{mCi} / \mathrm{mm})$ and $2.5 \mathrm{mM} \mathrm{L}-\left(1-{ }^{14} \mathrm{C}\right)$-glucose (sp.act. $4.0 \mathrm{mCi} / \mathrm{mm}$ ). Pre-incubation and incubation temperatures were $20^{\circ} \mathrm{C}$. The islet content of $\mathrm{D}$-glucose was determined by substracting the extracellular marker content of L-glucose. Mean \pm S.E.M. for 4 experiments

shown the rate of $\mathrm{D}$-glucose uptake at $20^{\circ} \mathrm{C}$ with $\mathrm{L}$ glucose as the extracellular marker. It is observed that equilibration is very rapid and appears complete at or prior to $5 \mathrm{~min}$ of incubation. At one minute, an estimate of the initial rate of uptake is possible with only 
$50 \%$ equilibration obtained at this time. Initial studies were carried out at $20^{\circ} \mathrm{C}$ in order to minimize subsequent D-glucose metabolism, abolish insulin secretion, and allow an accurate estimate of the initial rate of uptake. Comparable studies of the initial rate of $\mathbf{D}$. glucose entry have also been determined at $37^{\circ} \mathrm{C}$.

In Table 1 a comparison is made of initial rates of D-glucose uptake at one and five minutes with either L-glucose or sucrose as the extracellular marker. It is observed in this series of experiments that no significant difference is detected with either L-glucose or sucrose as the extracellular marker at incubation times of one or five minutes. In addition, it has been shown in comparing both L-glucose and sucrose directly that no significant differences are apparent in the diffusion rates of either extracellular markers at one or five minutes of incubation. This was demonstrated in a series of experiments in which only the two extracellular markers L-glucose and sucrose were present and differences in the diffusion of these markers into the extracellular spaces were measured. In the present studies both extracellular markers were employed in determining the uptake of $\mathrm{D}$-glucose.

Table 1. Determination of D-glucose uptake with extracellular markers $L$-glucose and sucrose

\begin{tabular}{lll}
\hline Extracellular & \multicolumn{2}{l}{ D-glucose Uptake (pmoles/islet) } \\
Marker & \multicolumn{1}{l}{ Incubation Time (min) } \\
\cline { 2 - 3 } & 1.0 & 5.0 \\
\hline Sucrose & $13.02 \pm 1.00(7)$ & $26.94 \pm 1.36(8)$ \\
L-glucose & $15.67 \pm 1.39(4)$ & $24.47 \pm 3.65(4)$ \\
\hline
\end{tabular}

Islets were incubated for either 1 or 5 min in media containing $16.5 \mathrm{mM} \mathrm{D}-\left(6-^{3} \mathrm{H}\right)$-glucose (Fig. 1) and $2.5 \mathrm{mM}$ L-(1-14 C)-glucose or $16.5 \mathrm{mM}$ uniformly ${ }^{14} \mathrm{C}$ labeled $\mathrm{D}$-glucose (sp.act. $0.6 \mathrm{mCi} / \mathrm{mm}$ ) and $5.0 \mathrm{mM}\left(6,6^{\prime} \cdot{ }^{3} \mathrm{H}\right.$ ). sucrose (sp.act. $2.0 \mathrm{mCi} / \mathrm{mm}$ ). Pre-incubation conditions were identical to Fig. 1. Mean \pm S.E.M. The number of individual observations in parentheses.

\section{Effect of Cytochalasin B on Hexose Uptake}

In these studies the solvent for cytochalasin B was dimethyl-sulfoxide, and this solvent was present at a concentration of $0.4 \%$ in the incubating mediums. It is shown in Table 2 that dimethyl-sulfoxide has no significant effect on the rate of entry of D-glucose after one minute of incubation. In this study, dimethyl-sulfoxide was present during both the pre-incubation and incubation periods.

Studies were performed to determine the effect of cytochalasin $\mathrm{B}$ on the initial rate of $\mathrm{D}$-glucose entry and at later incubation times when equilibration of the pancreatic B-cell would be complete. These studies were accomplished with both L-glucose and sucrose as extracellular markers. At one minute, cytochalasin $\mathbf{B}$ produced inhibition of $43 \%(P<0.025)$ with L-glucose and $64 \%(P<0.001)$ with sucrose as the respective extracellular marker as shown in Table $3 \mathrm{~A}$ and $B$. At three minutes an inhibition of $33 \%(P<$ $0.025)$ and $32 \%(P<0.005)$ was observed with the same respective extracellular markers on the rate of D-glucose entry into cytochalasin B treated islets. At an incubation period of $10 \mathrm{~min}$, in this case with sucrose as the extracellular marker, complete equilibration of D-glucose into the cytochalasin $B$ treated islets was observed.

Table 2. Effect of DMS on D-glucose uptake

\begin{tabular}{ll}
\hline $\begin{array}{l}\text { Experimental } \\
\text { conditions }\end{array}$ & D-glucose uptake (pmoles/islet/min) \\
\hline Control & $20.40 \pm 0.82(12)$ \\
DMS & $18.30 \pm 1.48(12)$ \\
\hline
\end{tabular}

Islets were incubated for one minute in media con-

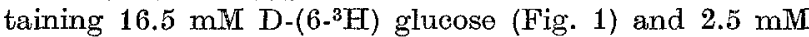
L- $\left(1-{ }^{14} \mathrm{C}\right)$-glucose. Pre-incubation were identical to Fig. 1. DMS was present at $0.4 \%$ during the pre-incubation and incubation periods. Mean \pm S.E.M. P-value for effect $<0.4$. The number of individual observations in parentheses.

Further studies were accomplished to determine if cytochalasin B inhibited in a similar manner the rate of entry of the hexose analogues 3-O-methyl-D-glucose and 2-deoxy-D-glucose. These studies were also performed at a temperature of $20^{\circ} \mathrm{C}$ with cytochalasin $\mathrm{B}$ $(15 \mu \mathrm{g} / \mathrm{ml})$ present in both the pre-incubation and incubation mediums. Cytochalasin B inhibited the initial uptake of 3-O-methyl-D-glucose 53\% $(P<0.001)$ after one minute of incubation (Table $4 \mathrm{~A}$ ). After $10 \mathrm{~min}$ of incubation, no significant difference was observed in the 3-0-methyl-D-glucose content between the control and cytochalasin $\mathrm{B}$ treated islets $(P<0.1)$. The initial uptake of 2-deoxy-D-glucose was inhibited $56 \%(P<0.001)$ by cytochalasin $\mathrm{B}$ exposure and after $10 \mathrm{~min}$ incubation no significant inhibition $(P<0.5)$ was observed with cytochalasin B treated islets (Table 4B). These findings indicate that cytochalasin B present in the pre-incubation and incubation media produced significant inhibition of the initial rate of uptake of D-glucose, 3-O-methyl-D-glucose, and 2deoxy-D-glucose. The final hexose equilibration of the cytochalasin $B$ treated islets under these conditions was complete by at least 10 min of incubation.

As noted earlier, an incubation temperature of $20^{\circ} \mathrm{C}$ was chosen initially to minimize insulin secretion and D-glucose metabolism during the longer incubation times used in these uptake studies (10 and $20 \mathrm{~min}$ ). Experiments were performed to determine if exposure to cytochalsin $B$ would inhibit $D$-glucose uptake at a incubation temperature of $37^{\circ} \mathrm{C}$. Significant inhibition of the initial rate of $\mathrm{D}$-glucose entry was observed at a temperature of $37^{\circ} \mathrm{C}$ when islets were pre-incubated and incubated in the presence of cytochalasin $B$ as shown in Table 5A. At a temperature of $37^{\circ} \mathrm{C}$, cytochalasin B produced $31 \%$ inhibition $(P<0.005)$ of the initial rate of D-glucose entry compared with $43 \%$ inhibition observed at a temperature of $20^{\circ}$ (Table $3 \mathrm{~A}$ ).

The exposure of pancreatic islets to cytochalasin B during the pre-incubation and incubation periods was used to duplicate conditions in which perifused islets 
pretreated with cytochalasin B demonstrated an enhancement of insulin release to both $D$-glucose and tolbutamide [3]. In Table 5B it is shown that if islets are not exposed to cytochalasin B during the pre-incubation period, and cytochalasin B is only present during the incubation period, no significant inhibition is observed on the initial rate of D-glucose entry at $37^{\circ} \mathrm{C}$. cose into pancreatic islets [12]. Recent experiments have shown that the washing procedure with collagenase isolated islets proves inaccurate in determining the kinetics of sugar transport. Problems encountered with the washing procedure are that the islet content of intracellular marker does not attain a final stable equilibrium and marked variations are apparent between individual experiments.

Table 3. Effect of cytochalasin $B$ on D-glucose uptake with either A) L-glucose or B) sucrose as extracellular marker

\begin{tabular}{|c|c|c|c|c|}
\hline \multirow{2}{*}{$\begin{array}{l}\text { Extracellular } \\
\text { marker }\end{array}$} & \multicolumn{4}{|c|}{$\begin{array}{l}\text { D-glucose uptake (pmoles/islet) } \\
\text { Incubation on time (min) }\end{array}$} \\
\hline & 1.0 & 3.0 & 10.0 & 20.0 \\
\hline $\begin{array}{l}\text { A) } L \text {-glucose } \\
\text { Control } \\
\text { Cyto-B }\end{array}$ & $\begin{array}{r}11.98 \pm 1.29(10) \\
6.75 \pm 1.25(7)\end{array}$ & $\begin{array}{l}26.67 \pm 1.68(8) \\
17.75 \pm 2.48(8)\end{array}$ & -- & $\begin{array}{l}37.01 \pm 4.30(3 \\
41.02 \pm 0.60(3\end{array}$ \\
\hline $\begin{array}{l}\text { B) Sucrose } \\
\text { Control } \\
\text { Cyto-B }\end{array}$ & $\begin{array}{r}15.91 \pm 1.30(8) \\
5.63 \pm 0.88(8)\end{array}$ & $\begin{array}{l}27.70 \pm 1.40(8) \\
18.70 \pm 2.10(8)\end{array}$ & $\begin{array}{l}40.01 \pm 1.44(6) \\
36.40 \pm 1.44(6)\end{array}$ & -- \\
\hline
\end{tabular}

A) Islets were incubated for 1,3 , and $20 \mathrm{~min}$ in media containing $16.5 \mathrm{mM} \mathrm{D}$ - $\left(6{ }^{-3} \mathrm{H}\right)$-glucose (Fig. 1 ) and $2.5 \mathrm{mM}$ $\mathrm{L}-\left(1{ }^{14} \mathrm{C}\right)$-glucose. B) Islet were incubated for 1,3 and $10 \mathrm{~min}$ in media containing $16.5 \mathrm{mM}$ uniformly ${ }^{14} \mathrm{C}$ labeled D-glucose (Table 1) and $5.0 \mathrm{mM}\left(6,6^{\prime}-3 \mathrm{H}\right.$ )-sucrose. Pre-incubation conditions were identical to Fig. 1 and cytochalasin $\mathrm{B}(15 \mathrm{\mu g} / \mathrm{ml})$ was present during both the pre-incubation and incubation periods. Mean \pm S.E.M. The number of individual observations in parentheses.

Table 4. Effect of cytochalasin $B$ on the uptake of glucose analogues A) 3-O-methyl-D-glucose and B) 2-deoxy-D. glucose

\begin{tabular}{|c|c|c|}
\hline \multirow[t]{2}{*}{ Hexose } & \multicolumn{2}{|c|}{$\begin{array}{l}\text { Hexose uptake (pmoles/islet) } \\
\text { Incubation time (min) }\end{array}$} \\
\hline & 1.0 & 10.0 \\
\hline \multicolumn{3}{|c|}{ A) 3-O-methyl-D-glucose } \\
\hline Control & $12.44 \pm 1.40(16)$ & $39.90 \pm 2.97(12)$ \\
\hline Cyto-B & $5.77 \pm 0$ & $32.35 \pm 2.24(12)$ \\
\hline \multicolumn{3}{|c|}{ B) 2-deoxy-D-glucose } \\
\hline Control & $24.42 \pm 0$ & $39.64 \pm 1.82$ \\
\hline Cyto-B & $10.71 \pm 0$ & $37.13 \pm 2.76$ \\
\hline
\end{tabular}

A) Islets were incubated for either 1 or $10 \mathrm{~min}$ in media containing $16.5 \mathrm{mM} \quad 3-0$-methyl-D-glucose- ${ }^{14} \mathrm{C}$ (Table 1) and 5.0 $\mathrm{mM}\left(6,6^{\prime}{ }^{3} \mathrm{H}\right)$-sucrose. B) Islets were incubated for either 1 or $10 \mathrm{~min}$ in media containing 16.5 $\mathrm{mM} 2$-deoxy-D-glucose ${ }^{14} \mathrm{C}$ labeled (Table 1) and $5.0 \mathrm{mM}$ $\left(6,6^{\prime}{ }^{3} \mathrm{H}\right)$-sucrose. Pre-incubation conditions were identical to Fig. 1 and cytochalasin $B$ was present during both the pre-incubation and incubation periods. Mean \pm S.E.M. The number of individual observations in parentheses.

\section{Comparison of Non-Wash and Wash Procedures}

Preliminary experiments were carried out using the washing procedure described by Hellman et al. [11] for removing contamination and extracellular label from islets after incubation. This system for measuring the kinetics of transport depends on the assumptions that such washing does not greatly affect the intracellular content of D-glucose, and equally important that the test substance itself does not alter the final intracellular content of D-glucose due to this loss in washing. Preliminary evidence using this washing technique suggested that cytochalasin B increased the uptake of Dglucose, 2-deoxy-D-glucose, and 3-O-methyl-D-glu-
Table 5. Effect of cytochalasin $B$ on D-glucose uptake $a^{t}$ $37^{\circ} \mathrm{C} A$ ) with and $B$ ) without preincubation

\begin{tabular}{lr}
\hline $\begin{array}{l}\text { Experimental } \\
\text { condition }\end{array}$ & D-glucose uptake (pmoles/islet/min) \\
\hline A) Preincubation & \\
Control & $13.72 \pm 0.93(12)$ \\
Cyto-B & $9.46 \pm 0.85(12)$ \\
B) Non-preincubation & \\
Control & $14.18 \pm 0.51(19)$ \\
Cyto-B & $13.20 \pm 0.44(19)$ \\
\hline
\end{tabular}

A) Islets were incubated for 1 min intervals in media containing $16.5 \mathrm{mM} \mathrm{D}-\left(6{ }^{3} \mathrm{H}\right)$-glucose (Fig. 1) and $2.5 \mathrm{mM}$ $\mathrm{L}-\left(1{ }^{14} \mathrm{C}\right)$-glucose. Pre-incubation conditions were identical to Fig. 1 except that temperatures were $37^{\circ} \mathrm{C}$, and both pre-incubation and incubation media contained cytochalasin B $(15 \mu \mathrm{g} / \mathrm{ml})$. B) Same experimental conditions as above except cytochalasin $B(15 \mu \mathrm{g} / \mathrm{ml})$ was only present during the incubation period. Mean \pm S.E.M. The number of individual observations in parentheses.

Hellman et al. $[9,13]$ also abandoned the washing procedure in determining rates of $\mathrm{D}$-glucose and 3-0methyl-D-glucose transport in microdissected islets obtained from obese-hyperglycemic mice and instead used a non-wash double label method similar to the one employed here.

A direct comparison of both systems on measuring the intracellular content of D-glucose in cytochalasin B treated islets after 20 min incubation is shown in Table 6. The non-wash procedure indicates a significantly lower D-glucose content in the control wash islets compared to the non-wash islets treated with cytochalasin B. In this experiment the non-wash con- 
trol was not included since it was shown to be identical in D-glucose content compared with the non-wash cytochalasin $B$ treated islets after $20 \mathrm{~min}$ of incubation (Table $3 \mathrm{~A}$ ). The cytochalasin $\mathbf{B}$ treated islets subjected to the washing procedure show a greater amount of intracellular marker compared with the control islets treated in the same manner. DMS alone at concentrations used in these experiments had no effect on the removal of intracellular hexose content by the washing procedure. It is possible that cytochalasin B may interfere with the washing of the islets and the removal of intracellular D-glucose which results in an artifactual increase in D-glucose.

Table 6. Effect of cytochalasin $B$ on D-glucose uptake using the non-wash and wash procedure

\begin{tabular}{ll}
\hline $\begin{array}{l}\text { Experimental } \\
\text { condition }\end{array}$ & D-glucose uptake (pmoles/islet) \\
\hline Non-wash & \\
Cyto-B & $41.13 \pm 2.26(9)$ \\
Wash & \\
Control & $16.01 \pm 2.31(9)$ \\
Cyto-B & $28.33 \pm 2.60(9)$ \\
\hline
\end{tabular}

Islets were incubated for $20 \mathrm{~min}$ at a temperature of $20^{\circ} \mathrm{C}$ in $16.5 \mathrm{mM}{ }^{14} \mathrm{C}$ labeled D-glucose (sp.act. $0.6 \mathrm{mCi}$ ) $\mathrm{mm}$ ) and $16.5 \mathrm{mM}\left(6,6^{\prime}{ }^{3} \mathrm{H}\right)$-sucrose (sp.act. $0.6 \mathrm{mCi} / \mathrm{mm}$ ). Cytochalasin B $(15 \mathrm{\mu g} / \mathrm{ml})$ was present during the preincubation and incubation periods. At the end of the incubation period the non-wash treated islets and wash treated islets were carried through the respective procedures as described in the Methods section. Mean \pm S.E.M. The number of individual observations in parantheses.

Table 7. Effect of cytochalasin $B$ on ${ }^{14} \mathrm{CO}_{2}$ production from uniformly labeled D-glucose

\begin{tabular}{lll}
\hline \multirow{2}{*}{$\begin{array}{l}\text { Experimental } \\
\text { condition }\end{array}$} & \multicolumn{2}{l}{ pmoles glucose oxidized/islet/2 $\mathrm{h}$} \\
\cline { 2 - 3 } Control & $\mathbf{8 . 3 \mathrm { mM } \text { D-glucose }}$ & $16.5 \mathrm{mM}$ D-glucose \\
Cyto-B & $\mathbf{4 9 . 3 8 \pm 4 . 2 3 ( 9 )}$ & $\mathbf{8 5 . 6 7} \pm 6.92(9)$ \\
\hline
\end{tabular}

Islets were pre-incubated for $25 \mathrm{~min}$ and incubated for $2 \mathrm{~h}$. Both the pre-ineubation and incubation periods were maintained at $37^{\circ} \mathrm{C}$ and both mediums contained cytochalasin B $(15 \mu \mathrm{g} / \mathrm{ml})$. The specific activity of $\mathbf{1 6 . 5}$ $\mathrm{mM}{ }^{14} \mathrm{C}$ uniformly labeled $\mathrm{D}$-glucose was $(0.6 \mathrm{mCi} / \mathrm{mm})$ and $8.3 \mathrm{mM} \mathrm{D}$-glucose $(1.3 \mathrm{mCi} / \mathrm{mm})$. Mean \pm S.E.M. The number of individual observations in parentheses.

\section{Effect of Cytochalasin B on Glucose Metabolism}

To determine the effect of cytochalasin $B$ on pancreatic islet glucose metabolism, the conversion of uniformly ${ }^{14} \mathrm{C}$ labeled D-glucose to ${ }^{14} \mathrm{C}$ labeled $\mathrm{CO}_{2}$ was measured. These studies were carried out over a two hour period of incubation during which the islets were exposed to cytochalasin $B(15 \mu \mathrm{g} / \mathrm{ml})$, the same concentration used in the transport experiments. Two concentrations of D-glucose were used, one representing approximately one-half the maximal rate of glucose oxidation and the other a maximum rate of glucose oxidation. As shown in Table 7 cytochalasin B exerted no effect on the production of labeled $\mathrm{CO}_{2}$ at $\mathrm{D}$-glucose concentrations of either $8.3 \mathrm{mM}$ or $16.5 \mathrm{mM}$. It was also demonstrated in these studies that dimethylsulfoxide had no significant effect on the overall glucose metabolism of pancreatic islets to $\mathrm{CO}_{2}$.

\section{Discussion}

Cooperstein and Lazarow [14] were first to demonstrate that glucose transport in fish islets is stereo-specific for the D-isomer. Hellman et al. have employed the double label non-wash method to demonstrate the carrier-mediated nature of the D-glucose transport system [9] and the capacity of this system to transport 3-O-methyl-D-glucose [13] in microdissected islets of obese-hyperglycemic mice. In the present studies evidence is presented indicating that L-glucose and sucrose are restricted to the extracellular space in collagenase isolated islets. This evidence suggests that the permeability of the plasma membrane to L-glucose and sucrose may be small or zero as it is in hand-dissected islets obtained from obese hyperglycemic mice [9]. The present studies also indicate that L-glucose does not differ from sucrose in serving as an extracellular marker for rapid determination of the initial rate of $\mathrm{D}$-glucose entry into collagenase isolated pancreatic islets. It has also been shown that the washing of collagenase isolated islets to remove both contaminating and extracellular label affects the intracellular content of D-glucose, and thus is inaccurate for studies of the kinetics of hexose transport. In the present investigation the double-label non-wash procedure was used to determine the amount of extracellular label present in the pancreatic islet. The reason for the selective washing-out of intracellular D-glucose content from the control islets compared with cytochalasin B treated islets by the washing procedure is at present unclear.

A consideration in the non-wash procedure is whether under insulin stimulating conditions, the normally impermeable extracellular markers, L-glucose and sucrose, would have access to the intracellular content of the B-cell due to pinocytosis. This possibility is precluded or minimized in the present study by inhibiting insulin release with an incubation temperature of $20^{\circ} \mathrm{C}$ and by determining only initial rates of transport at a temperature of $37^{\circ} \mathrm{C}$.

The present study indicates that cytochalasin $B$ exerts an inhibitory effect on the initial rate of $\mathrm{D}$-glucose, 3-O-methyl-D-glucose, and 2-deoxy-D-glucose entry. This inhibition depends on exposing the islets to cytochalasin B prior to exposure to a insulin stimulatory concentration of $\mathrm{D}$-glucose, $16.5 \mathrm{mM}$, or the hexose being studied. This inhibition is present at incubating temperatures of both $20^{\circ}$ and $37^{\circ} \mathrm{C}$, and is overcome after 10 min of incubation. However, the inhibition under these conditions is not observed if cyto- 
chalasin B is present only during the incubation period and absent during the pre-incubation period. It must also be emphasized that these latter experiments were carried out at $37^{\circ} \mathrm{C}$ where failure to detect an immediate effect of cytochalasin may be related to the extreme velocity with which $\mathrm{D}$-glucose equilibrates across the membrane.

Cytochalasin B has been shown to be a reversible inhibitor of sugar uptake in several different types of cells. It has been demonstrated to inhibit 2-deoxy-Dglucose uptake in chick embryo fibroblasts, epithelial cell-types from rat liver, and this same cell line transformed by the Harvey strain of the murine Sarcoma virus [4]. Cytochalasin $B$ has also been shown to inhibit potently the transport of glucose, 2-deoxy-glucose, and glucosamine by Novikoff hepatoma cells in suspension culture without affecting their intracellular phosphorylation and metabolism [5]. 2-deoxy-glucose transport in this latter study appeared to be inhibited by cytochalasin $\mathrm{B}$ in a simple competitive manner. It has been shown similarly that eytochalasin B blocks transport of glucose into both leukocytes and fibroblasts which then leads to suppression of glycolysis [15]. The various inhibitory effects of cytochalasin $B$ on leukocyte metabolism and function exhibit a dose response relation and are all rapid and reversible. This inhibitory effect on hexose transport has also been observed by Mizel and Wilson [16], in Hela, 3T3, HTO rat hepatoma and chick embryo heart cells. Inhibition of hexose transport was immediate and completely reversible, but appeared to be noncompetitive in this study.

Cytochalasin B $(1-20 \mu \mathrm{g} / \mathrm{ml})$ has been shown to produce a significant enhancement in the release of insulin following stimulation of isolated islets with either glucose or tolbutamide $[1,2,3]$. Orei et al. $[1,2]$ have suggested that the enhancing effect of cytochalasin $B$ on insulin release may be due to the disruption of the microfilamentous web of the beta cell by this agent, and thus the removal of a potential barrier to the release of beta granules by emiocytosis. The demonstration that cytochalasin B inhibits the rate of uptake of $D$-glucose by isolated islets suggests that the agent is affecting the beta cell membrane. The basic mechanism of the paradoxical effect of inhibition of D-glucose uptake and enhancement of glucose-induced insulin release in beta cells remains to be determined.

\section{References}

1. Orci, L., Gabbay, K.H., Malaisse, W.J.: Pancreatic beta-cell web: Its possible role in insulin secretion. Science 175, 1128-1130 (1972)

2. Malaisse, W.J., Hager, D., Orci, L.: The stimulussecretion coupling of glucose-induced insulin release. Diabetes (Suppl. 2) 21, 594-604 (1972)

3. Lacy, P.E., Klein, N.J., Fink, C.J.: Effect of cytochalasin $B$ on the biphasic release of insulin in perifused rat islets. Endocrinology 92, 1458-1468 (1973)

4. Kletzien, R.F., Perdue, J.F., Springer, A.: Cytochalasin A and B. J. biol. Chem. 247, 2964-2966 (1972)

5. Estensen, R.D., Plagemann, P.: Cytochalasin B: Inhibition of glucose and glucosamine transport. Proc. nat. Acad. Sci. (Wash.) 69, 1430-1434 (1972)

6. Lacy, P.E., Kostianovsky, M.: Method for isolation of intact islets of Langerhans from rat pancreas. Diabetes 16, 35-39, (1967)

7. Lacy, P.E., Young, D.A., Fink, C.J.: Studies on insulin secretion in vitro from isolated islets of the rat pancreas. Endocrinology 83, 1155-1161 (1968)

8. Renold, A.E., Martin, D. B., Dagenais, Y.M., Steinke, J., Nickerson, R., Sheps, M.C.: Measurement of small quantities of insulin-like activity using rat adipose tissue. I. A proposed procedure. J. clin. Invest. 39, 1487-1498 (1960)

9. Hellman, B., Sehlin, S., Täljedal, I.B.: Evidence for mediated transport of glucose in mammalian pancreatic B cells. Biochim. biophys. Acta 241, 147-154 (1971)

10. Lowry, O.H., Passonneau, J.V.: A flexible system of enzymatic analysis, p. 226. New York: Academic Press 1972

11. Hellman, B., Sehlin, J., Täljedal, I.B.: Transport of amino-isobutyric acid in mammalian pancreatic B-cells. Diabetologia 7, 256-265 (1971)

12. MeDaniel, M.L., Lacy, P.E.: Effect of cytochalasin $\mathrm{B}$ on hexose uptake in collagenase isolated pancreatic islets. Diabetes (Suppl. 1) 22, 296 (1973)

13. Hellman, B., Sehlin, J., Täljedal, I.: Transport of 3-0-methyl-D-glucose in mammalian pancreatic Bcells. Pflügers Arch. 340, 51-58 (1973)

14. Cooperstein, S.J., Lazarow, A.: Uptake of glucose by islet of Langerhans and other tissues of the toadfish Opsanus tau. Amer. J. Physiol. 217, 1784-1788 (1969)

15. Zigmond, S.H., Hirsch, S.G.: Cytochalasin B: Inhibition of D-2-deoxyglucose transport into leukocytes and fibroblasts. Science 176, 1432-1434 (1972)

16. Mizel, S.B., Wilson, L.J.: Inhibition of transport of several hexoses in mammalian cells by cytochalasin B. J. biol. Chem. 247, 4102-4105 (1972)

Dr. M. L. McDaniel

Department of Pathology

Washington University School of

Medicine

St. Louis, Missouri 63110

USA 